\title{
Influence of marine and freshwater connectivity on the dynamics of subtropical estuarine wetland fish metapopulations
}

\author{
Marcus Sheaves*, Ross Johnston \\ School of Marine and Tropical Biology, James Cook University, Townsville, Queensland 4811, Australia
}

\begin{abstract}
Estuarine wetlands have received little study in dry tropical and subtropical areas despite the fact that unpredictable rainfall makes their temporal continuity tenuous. In fact, many of these wetlands exist for much of the time as isolated pools that are remnants of extensive areas of shallow water that occur during infrequent flooding. Among the most important functional components of estuarine wetlands are the multifaceted connections between wetland units, and between wetlands and adjacent habitats, that maintain wetland integrity and allow fish to access them as nurseries. As the principal determinants of the likelihood of recolonisation, these connections are critical to metapopulation dynamics. To understand the ways in which the unique patterns of connectivity in these wetlands influence metapopulation dynamics and the compositions of fish fauna, we investigated patterns of physical and biological connectivity among estuarine wetland pools in the Fitzroy River delta of Australia's dry subtropics. Ten wetland pools ranging in salinity from fresh to hyperhaline, and differing in periodicity of connection from weeks, through months, to years were sampled regularly from February 2004 to May 2005, using cast nets. There were 4 distinct categories of pools isolated freshwater pools, in-stream freshwater pools, regularly connected poikilohaline pools (pools where salinity varied over time from close to fresh to hyperhaline) and infrequently connected poikilohaline pools. The catch per unit effort and size structures of fish fauna of the different pool categories reflected connectivity, which determined the extent to which both marine- and freshwaterspawned species could re-colonise pools following local extinction. Overall, factors related to recolonisation were more important than those related to extinction in determining fish assemblage structures. Moreover, in contrast to many other metapopulation situations many extinction factors were heavily influenced by connectivity rather than being independent of it.
\end{abstract}

KEY WORDS: Dry tropics · Estuarine wetlands · Subtropical wetlands · Metapopulation connectivity Wetland integrity $\cdot$ Nursery grounds $\cdot$ Faunal composition

\section{INTRODUCTION}

Estuarine wetlands occur adjacent to estuaries around the world (Gilmore 1995, Laffaille et al. 2000, Bruinsma 2001). They provide diverse habitats for a wide variety of organisms (Semeniuk et al. 2000, Adamowicz \& Roman 2005), and because they often encompass a complexity of habitats (Rozas \& Hackney 1983) that vary substantially over time, they can promote the co-existence of diverse fauna (Gilmore 1995, Gelwick et al. 2001). Estuarine wetlands are important nursery (Costa et al. 2001, Sheaves et al. 2007a) and feeding grounds (Shreffler et al. 1992, Baker \& Sheaves 2007), and provide critical linkages to other habitats (Sheaves 2005). Because of their widespread occurrence, diversity of form and function, and floral and faunal richness, estuarine wetlands are of substantial ecological, economic and cultural importance in a global context (Mazzotti et al. 2005).

Multifaceted connections between wetland units (e.g. individual pools, stream reaches, swamps), and between wetlands and adjacent habitats, are among 
the most important functional components of estuarine wetlands (Ray 2005, Sheaves 2005). The integrity of estuarine wetlands is maintained by physical connections (Chabrerie et al. 2001) that are crucial in determining the extent of water level fluctuations and the temporal duration of aquatic conditions (Ruetz et al. 2005), and in allowing mobile species like fish to utilise a range of different habitats often vital for proper nursery ground function (Brockmeyer et al. 1997, Sheaves 2005), to enter temporal refuges from predation (Bishop et al. 1995, Baker \& Sheaves 2005), and to access productive feeding grounds (Shreffler et al. 1992).

Many wetlands are predictably connected to other systems (Rozas \& Hackney 1983), although these connections may be infrequent (Laffaille et al. 2000). In contrast, in many Australian estuarine wetland connections are intermittent and unpredictable. Most Australian estuaries $(68 \%)$ are located in the wet or dry tropics or subtropics (Eyre 1998). Most are shallow, due to tectonically stable geology and low coastal relief (Eyre 1998), and, except in the highest rainfall areas, freshwater inflow is highly episodic (Sheldon \& Thoms 2006). Together, shallow channels, low gradients and episodic freshwater flows result in fragmented and often unpredictable connections being the norm in many Australian estuarine wetlands. This fragmentation leads to estuarine wetlands in these systems existing for much of the time as series of isolated pools, with a diversity of salinity regimes, degrees of permanence, and potentials for connectivity. This range of pool conditions leads to fish fauna comprised of variable mixtures of fresh and estuarine species (Sheaves et al. 2007). In these dry tropical and subtropical wetlands, connectivity (physical events that allow materials or organisms to move between spatially or temporally separate habitats or populations) is the principal agent determining the likelihood of recolonisation, making it critical to metapopulation dynamics.

Although the metapopulation concept (a group of local populations inhabiting more or less discrete patches of habitat [Hanski 1998] where regional persistence is governed by extinction and recolonisation [Freckleton \& Watkinson 2002]) has often been applied to the marine environment, its validity has often been questioned because many marine systems are open and populations often lack any real probability of extinction (Smedbol et al. 2002, Kritzer \& Sale 2004). In contrast, estuarine wetlands in the dry tropics and subtropics fulfil the criteria for the development of metapopulation dynamics (Hanski 1999). Their discrete 'patches' may be occupied by local reproducing populations that have measurable risks of extinction, and while periodic connections provide the opportu- nity for recolonisation following local extinctions, pools are isolated enough to make completely synchronous dynamics unlikely. The metapopulation view of spatial organisation links local and regional dynamics (Freckleton \& Watkinson 2002) and seeks to provide a structured understanding of the balance between extinction and recolonisation processes in driving biological patterns. Consequently, it has played a prominent role in the prevention of overexploitation of marine resources (Grimm et al. 2003) and the development of marine protected areas (MPAs) as tools for marine fisheries and conservation management (Russ 2002).

The fragmented and often unpredictable connections common in Australian dry subtropical estuarine wetlands, together with the complication of connections resulting from both stream flow and tides, means it is difficult to predict the relative importance of recolonisation, extinction and demographic change on metapopulation dynamics and the composition of fish assemblages. To understand the influence of these factors, we investigated patterns of physical and biological connectivity among estuarine wetland pools in Australia's dry subtropics, ranging in salinity from fresh to hyperhaline, and differing in periodicity of connection from weeks, through months, to years. We addressed the following questions: (1) How do tidal and freshwater connections interact to produce biological connectivity? (2) To what extent do variations in connectivity affect fish assemblages? (3) How temporally stable are the pool assemblages, and to what extent are faunal dynamics synchronised within and among pool types? (4) How important are extinctionand recolonisation-related factors in determining fish assemblage composition?

\section{MATERIALS AND METHODS}

Study area and study sites. The Fitzroy River (Fig. 1) is the largest coastal river system in central Queensland, Australia, draining a catchment of more than $140000 \mathrm{~km}^{2}$, with an estuary about $65 \mathrm{~km}$ in length. Interspersed across the Fitzroy River delta adjacent to the estuary are a variety of semi-permanent estuarine wetland pools that are intermittently connected to the estuary. These pools represent persistent remnants of extensive shallow-water wetland nursery habitats that cover much of the Fitzroy River floodplain during major flooding (Sheaves et al. 2006).

Seven pools adjacent to the Fitzroy River estuary, which could be accessed reliably (depending on road conditions and willingness of land owners), and without major human-constructed impediments (e.g. dams, bund walls), were studied (Fig. 1, Table 1). Three of these comprised an upstream sequence in 12 Mile 


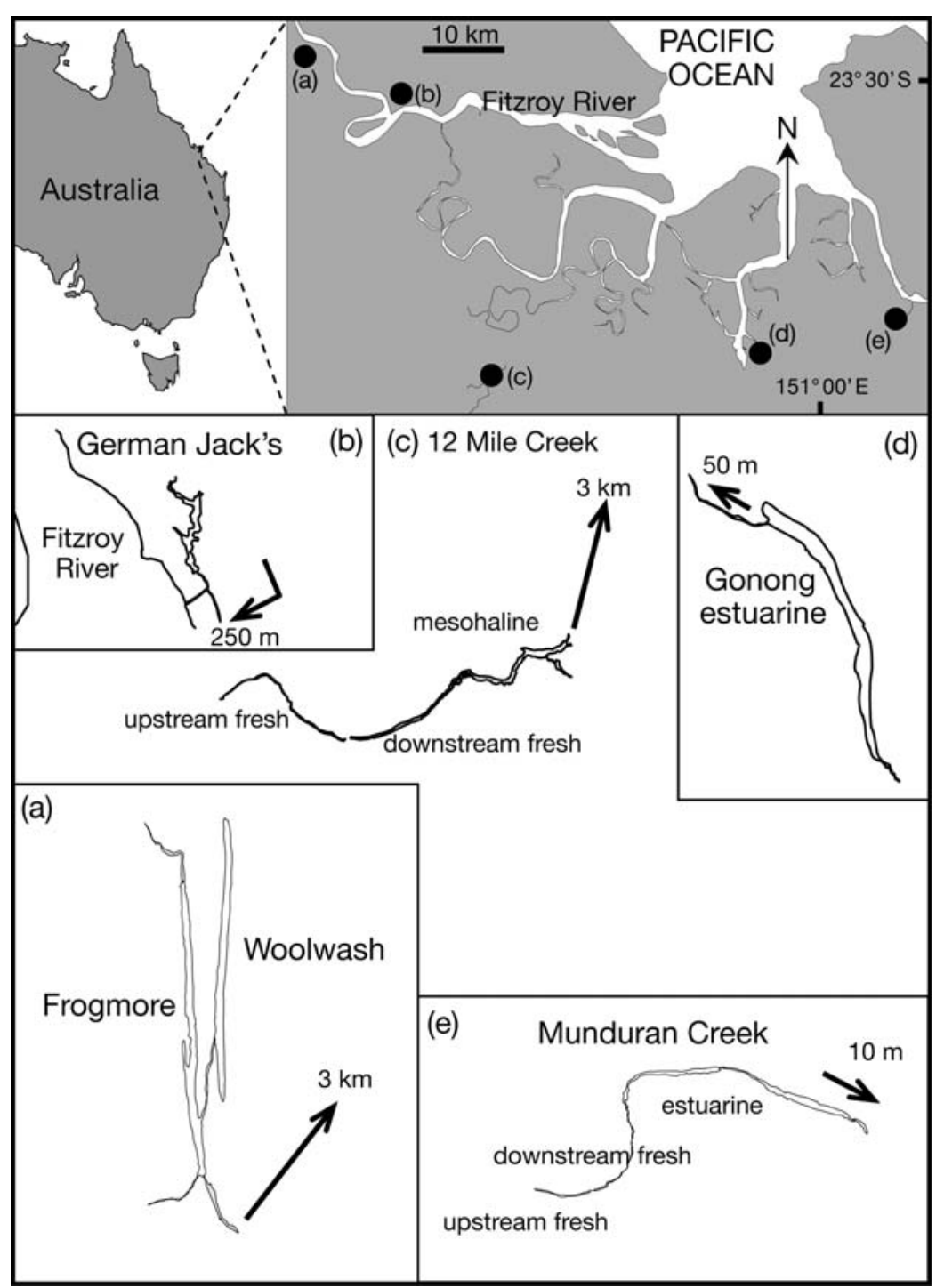

Fig. 1. Location of the Fitzroy delta study sites. Solid circles indicate location of pools. Arrows with distances indicate direction and approximate distance to connect to the Fitzroy estuary. Detail maps (a-e) are to differing scales (see Table 1 for sizes)

Creek, 2 (Frogmore and Woolwash) were adjacent isolated freshwater pools, and 2 (Gonong and German Jack's) were adjacent to branches of the Fitzroy River estuary. In addition, sampling was extended to include a series of 3 pools in Munduran Creek, which flows into the 'Narrows', a body of water connecting the Fitzroy River with Port Curtis to the south.

The study pools comprised a variety of salinity regimes due to differences in regularity of freshwater input and tidal connection (Table 1) including both freshwater (Frogmore, Woolwash, 12 Mile up- and downstream, Munduran up- and downstream) and poikilohaline pools, where salinity varied over time from close to fresh to hyperhaline (Dahl 1956) (12 Mile mesohaline, Gonong and Munduran estuarine, German Jack's hyperhaline). Connectivity also varied greatly (Table 1), with some pools directly connected to the estuary on the highest tides, and others only indirectly during major flooding of the river or as a result of local storm rainfall. Consequently, the set of pools (Table 1) provided (1) a variety of salinity regimes, (2) 2 sets of pools in an upstream sequence (12 Mile and Munduran Creeks), and (3) pools that were part of semi-permanent streams as well as those that were isolated. Additionally, the nature of connections to the estuary varied among pools with direct marine connections. Gonong and Munduran estuarine were separated from the estuary by short $(<50 \mathrm{~m})$ rock and rubble bars that were flooded by most spring tides. German Jack's hyperhaline was connected by a short (250 m), poorly defined channel during the highest spring tides ( 4 to 8 times $\mathrm{yr}^{-1}$ ) and by sheet flow across the saltpan during extreme high tides. 12 Mile mesohaline had no defined connecting channel, only connecting to the estuary by sheet flow across a broad (ca. $3 \mathrm{~km}$ ) saltpan during the highest spring tides ( 2 to 4 times $\mathrm{yr}^{-1}$ ).

Sampling. Sampling was conducted from February 2004 to May 2005 at 3 monthly intervals, timed to coincide with the highest spring tides, when tidal connection was likely. Only 3 sites (Frogmore, 12 Mile mesohaline, 12 Mile upstream) were sampled during the initial sampling trip in February 2004. Most sites were sampled repeatedly from May 2004 to May 2005, with sampling time aligned with the 'wet' (February), 'post-wet' (May), 'dry' (August) and 'pre-wet' (November) seasons. Extremely shallow water depths and impassable access roads prevented sampling at Munduran upstream and downstream, and German Jack's on a number of occasions. Although not initially included in the study, Woolwash was sampled in May 2004, and February and May 2005, to provide spatial replication of changes in adjacent Frogmore, the only other large pool in the study. Logistic and time constraints meant that more regular sampling was not possible, and initial faunal similarity and a lack of connection of either pool to any other system throughout the study meant 


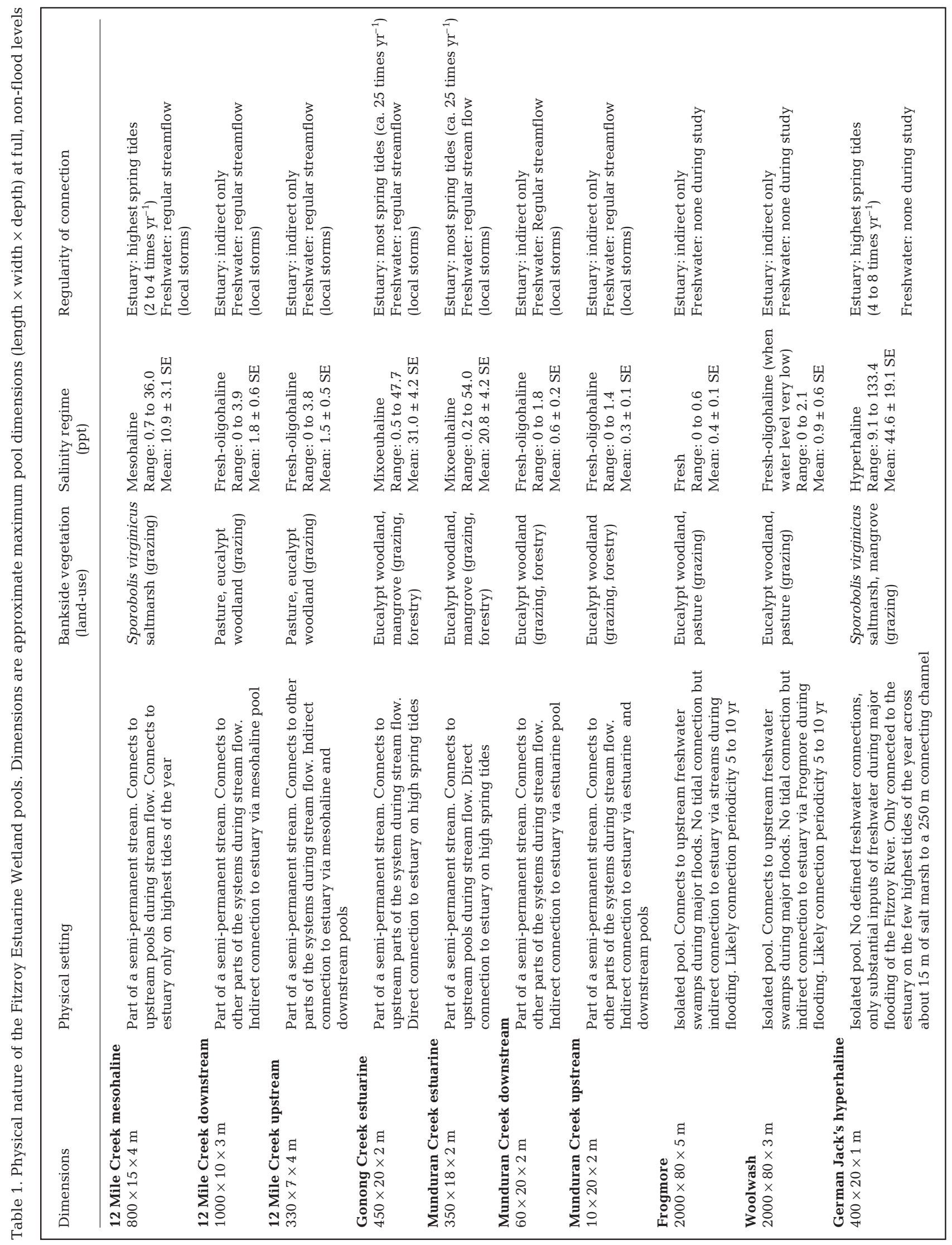


that the 3 sampling events provided the opportunity to detect any gross differences in faunal trajectories.

Fish were sampled using cast nets $(18 \mathrm{~mm}$ mesh, $4.29 \mathrm{~m}$ diameter). Cast nets were selected from a broad range of gears trialled because of their ability to be deployed over the full range of conditions encountered in the diversity of pools (Sheaves et al. 2006, Stevens 2006), because they reliably represent pool fish assemblages (Stevens 2006, Stevens et al. 2006), and because almost all fish could be released without injury (Schorr et al. 1995). Although it would have been preferable to sample proportionally to pool area, the need to sample small pools adequately and the great differences in sizes between pools meant this was not feasible. Instead, sampling aimed to produce the best estimates of catch per unit effort (CPUE) by collecting as many independent samples as possible from the smaller pools while distributing as many samples as possible evenly over larger pools within the limits of logistics. At least 50 cast net samples were collected from each site whenever there was sufficient area for 50 independent samples. To assure independence, net spacing was kept to a minimum of $5 \mathrm{~m}$. In another study in northern Australian estuaries, Johnston et al. (2007) found no influences on catches in successive nets spaced at $2 \mathrm{~m}$. In some cases, the area available became limited as pools dried or because of dense growths of water plants. Although data from sites with low replication extend the range of pools investigated, low replication means those data should be treated with caution: abundant species are likely to be represented reasonably well, but less common species are likely to be underrepresented. In each pool, sampling effort was distributed as evenly as possible over the whole area, with samples collected across the full range of depths from edges to pool centres.

Cast netting was conducted from a small boat fitted with an electric motor to minimise site disturbance. Net throws were not used if (1) they did not sample more than an $85 \%$ of the maximum sample area (estimated by eye), (2) the net became snagged on any structure, (3) it appeared that a site was disturbed during boat positioning, or (4) if the net operator's shadow encroached onto the proposed sampling area. Any variability in sampling area (i.e. differences in the surface area of net throws) was randomly distributed throughout the study; therefore, any biases added variability to the data in a random manner. Measurements from net throws on land indicated that actual sampling area was considerably below theoretical maximum but not highly variable (net mean area $=7.35 \mathrm{~m}^{2} ; \mathrm{SE}=0.40$, $\mathrm{n}=50$ ).

Salinity (at $20 \mathrm{~cm}$ depth), turbidity, temperature, $\mathrm{pH}$ and pool depth were recorded on each sampling trip as well as on an additional trip in December 2004 in response to high tides and freshwater stream flows. Connection events (the flow of water through connecting channels or over low points between pools) were recorded during sampling periods using simple automatic connection gauges (Sheaves et al. 2006) placed at each potential connection point. The gauges consisted of $30 \mathrm{~mm}$ long vials attached sequentially along a $2 \mathrm{~m}$ long pole set vertically into the substrate. Each vial had 2 holes drilled into it, one at the mid-point of the vial to allow water to enter and one just below the lip of the lid to let air escape thus preventing pressure build-up that might prevent water entering the lower hole. Rainfall was deflected away by the overhanging lids of the vials. Recorded connection events during sampling trips were supplemented with information on connections during intervening periods supplied by farmers with grazing properties adjacent to the pools. Tidal data were supplied by the Technical Services Division of the Queensland Environmental Protection Agency.

Data and statistical analyses. Captured fish were placed into $25 \mathrm{~mm}$ size classes by eye and numbers in each size class recorded. Most fish captured in cast nets were released unharmed, except for a small number of fish retained to validate in-field size classing. The fish that were retained were euthanised in an ice-water slurry (Ethics Approval No.: A852_03). Fish were categorised as marine or freshwater spawners based on spawning locality or environment occupied. The categorisation was principally based on information in FishBase (Froese \& Pauly 2007) or Pusey et al. (2004).

Fish assemblage structure. CPUE of species that occurred in at least $5 \%$ of nets (McCune \& Grace 2002) was analysed using non-metric multidimensional scaling (nMDS) based on Bray-Curtis dissimilarities, employing PRIMER analytical software. Data were $\log (x+1)$ transformed prior to analysis to ensure that highly abundant species did not swamp the results of multivariate analyses (McCune \& Grace 2002). Although analysis was conducted on the full dataset, the ordination of this dataset was too crowded for visual display. Consequently, ordination of means of sites for each trip (that produced the same pattern and interpretations) is presented. Coherent groups of samples were defined by a SIMPROF test at a significance level of 0.01 . SIMPROF is a permutation test of the null hypothesis that samples within a cluster group do not differ in multivariate structure (Clarke \& Gorley 2006). This group structure was superimposed on the nMDS ordinations. Information on the strength and nature of the correlation of species with the nMDS space was added to the ordination biplot as vectors indicating the direction of greatest increase in density of species most highly correlated with the space. The 
direction of these vectors was determined by regression of each species on the nMDS space, with the length of vectors reflecting the $\mathrm{R}^{2}$ value for each regression, thus indicating the strength of correlation.

Orthogonal polynomial contrasts were used to investigate the nature of changes in CPUE and mean size over time. Orthogonal polynomial contrasts are one degree of freedom comparisons that enable trends across equally spaced treatment levels to be decomposed into successive polynomial components (Sokal \& Rohlf 1981), allowing evaluation of the presence and degree of any significant curvature. In this case polynomial contrasts were used to evaluate if apparent changes were significant, and whether they were mainly linear (simple increases or decreases), or substantially curved (quadratic or cubic). Mean fork length (FL) was used as a summary index to allow investigation of patterns of change in size over time. In cases where sample sizes were large enough for evaluation of size structures, distributions of FL were unimodal and means and medians similar. However, in a number of cases sample sizes were too small for reliable evaluation so the validity of the mean could not be determined for the whole dataset. Consequently, interpretation of size structures was limited to evaluating gross patterns of change over time.

Extinction versus recolonisation. Following the approach of Magnuson et al. (1998) we evaluated the relative importance of extinction and recolonisation in structuring the fish fauna of the Fitzroy pools by investigating the relationships between a set of extinction and recolonisation variables, and assemblage composition.

Extinction variables likely to influence the suitability of pools for particular species included (1) 5 measures of physical variables for each trip: mean salinity, mean temperature, mean $\mathrm{pH}$, mean turbidity, and maximum depth; (2) mean piscivorous fish CPUE; and (3) 5 summary variables describing the overall physical nature of each pool: surface area (at maximum non-connection water level), depth range, salinity range, turbidity range, and salinity regime. Salinity regimes were categories (modified from Por 1972) representing the typical salinity profiles of the pools over most of the study period-Fresh: Frogmore, Woolwash, Munduran upstream and downstream; Oligohaline (0.5 to $5 \%$ ): 12 Mile upstream and downstream; Mesohaline (5 to 18\%): 12 Mile mesohaline; Mixoeuhaline (30 to $40 \%$ ): Gonong, Munduran estuarine; Hyperhaline (>70 \%): German Jack's. Although piscivorous bird predation was also likely to be an important factor, it was not included in the analysis because rapid temporal fluctuations in abundance meant that there was no reasonable way of representing piscivorous bird predation pressure on a pool.
Recolonisation variables were estimates of (1) regularity of estuarine connection ( 0 to 3 rank categories); (2) regularity of freshwater connection (0 to 3 rank categories); (3) upstream connection distance (distance along the most likely water course to the nearest source of freshwater colonists - possibly another pool in the study); (4) downstream connection distance (distance along the most likely water course to the nearest source of estuarine colonists); (5) freshwater connection distance (distance along the most likely water course to the nearest source of freshwater colonists outside of the pools studied); and (6) estuarine connection distance (distance along the most likely water course to the estuary proper).

The importance of extinction and recolonisation variables on assemblage composition were analysed using a multivariate classification and regression tree (mCART) (De'ath 2002), utilising TreesPlus software. mCARTs recursively partition data into increasingly homogeneous subsets. Splits close to the root of the tree are typically more important (yield greater improvement in the fit of the model) than those that are closer to the bottom of the tree. Selection of the final tree models was conducted using 10-fold cross validation, with the 1-SE tree (the smallest tree with cross validation error within $1 \mathrm{SE}$ of that of the tree with the minimum cross validation error) selected as the final tree model. This procedure is generally considered to produce valid, biologically interpretable trees (Breiman et al. 1984, De'ath 2002). The importance of each variable was evaluated by its occurrence in the final 1-SE tree. Additionally, the relative importance of variables was assessed to ensure that variables with high overall importance, which were not the best predictors for particular splits, were not overlooked. Importance is determined using each variable at each tree branching, with the best overall classifier given a relative importance of $100 \%$.

\section{RESULTS}

\section{Physical connections}

The wetland pools showed 4 patterns of salinity. Salinity remained close to zero throughout the study at the isolated (Frogmore, Woolwash) and in-stream freshwater sites (12 Mile upstream and downstream fresh, Munduran upstream and downstream fresh). Salinity increased steadily in Gonong and Munduran estuarine pools (Fig. 2a) through most of 2004, from low levels following flooding in early the year, to hyperhaline (ca. $50 \%$ ) conditions in November. The development of hyperhaline conditions is typical of upper estuarine areas of the Fitzroy delta (Webster et al. 2003), and is a function of low freshwater inflow 


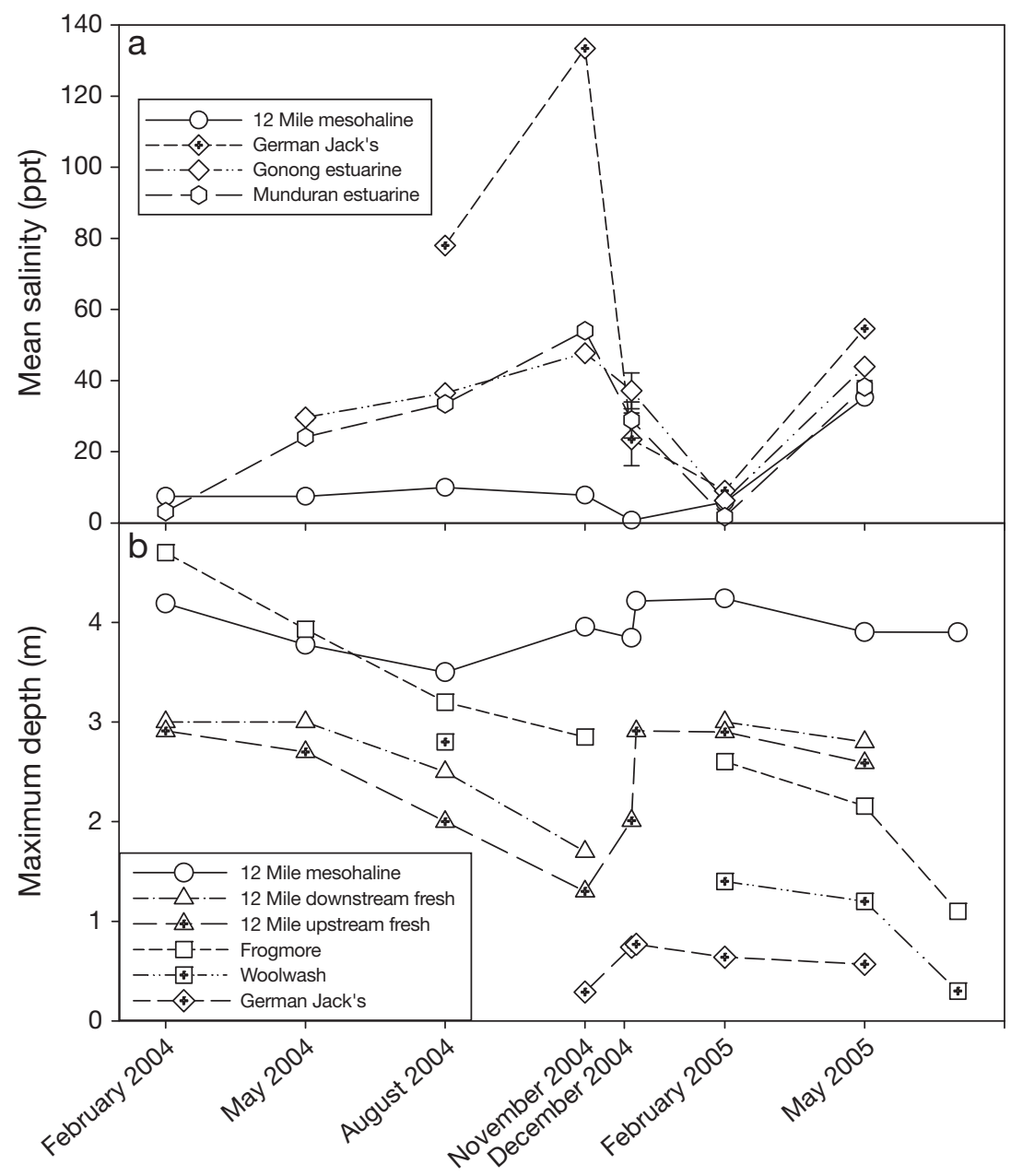

Fig. 2. Patterns of change over time of (a) salinity in 4 estuarine wetland pools influenced by tidal connections, and (b) maximum depth of 6 estuarine wetland pools lacking regular tidal connections. Salinity error bars are SEs (note most are smaller than the symbol size)

coupled with evaporation. Following freshwater flow from extensive rainfall, during late 2004 and early 2005, salinities declined to low levels by February 2005 then increased again to May 2005 following the cessation of freshwater inflow. Salinities of 12 Mile mesohaline followed a similar trajectory, but a lack of marine connections during most of 2004 produced only a small increase in salinity (Fig. 2a). The shallow nature of German Jack's (Fig. 2b), and the lack of any freshwater feeder stream, meant that evaporation prior to November 2004 had produced strongly hyperhaline conditions. Subsequently, heavy local rainfall in late 2004 and early 2005 led to salinities comparable to the other poikilohaline sites. Patterns of depth in pools without regular tidal connections (Fig. 2b) reflected their degrees of connection to freshwater streams. A lack of any stream connections during the study saw levels in Frogmore and Woolwash decline consistently over the study period. In contrast, despite initially declining at a similar rate to Frogmore and Woolwash, streamflow during late 2004 and 2005 refilled the two 12 Mile freshwater pools (Fig. 2b). The 12 Mile mesohaline showed slow depth changes, buffered by an additional input of freshwater from local rainfall early in November 2004.

The complex interaction between marine and freshwater connections is illustrated by the patterns of salinity and depth in 12 Mile mesohaline (Fig. 3b). Period 1: lack of connection prior to August 2004 resulted in a fall in depth and a slight increase in salinity. Period 2: depth increased and salinity fell following local rainfall prior to November 2004. Period 3: pool level fell but salinity increased due to a marine connection during November spring tides. Period 4: extensive flooding from storm rainfall filled the pool and reduced salinity. Period 5: cessation of freshwater flow and marine connections led to a slight fall in level and increased salinity. Period 6: major tidal connection increased pool level and salinity. Period 7: salinity increased and pool level fell due to evaporation and lack of connections. A marine connection on a $5.3 \mathrm{~m}$ tide on 13 November 2004 suggested that a tide height similar to the $5.2 \mathrm{~m}$ needed to connect Gonong and Munduran estuarine pools was adequate for marine connection at the 12 Mile mesohaline pool. However, despite many predicted tides exceeding $5.2 \mathrm{~m}$ during 2004 (Fig. 3a), no marine connections occurred at 12 Mile mesohaline until November 2004, apparently due to a combination of factors. Firstly, there were considerable variations between predicted and realised tidal heights, with realised heights of high tides at the Port Alma tide gauge, at the mouth of the estuary leading to 12 Mile Creek, varying by up to $20 \mathrm{~cm}$ from tidal predictions (Fig. 4). During 2004 these tidal anomalies would have had a strong damping effect on estuarine connectivity because most spring tides failed to reach their predicted tidal heights. Secondly, freshwater streamflow in November 2004 converted the previously dry, cracked surface of the $3 \mathrm{~km}$ wide saltpan that led to 12 Mile mesohaline into damp mud, probably reducing absorption of tidal water and hydraulic friction considerably. In fact, all marine connections occurred following fresh- 


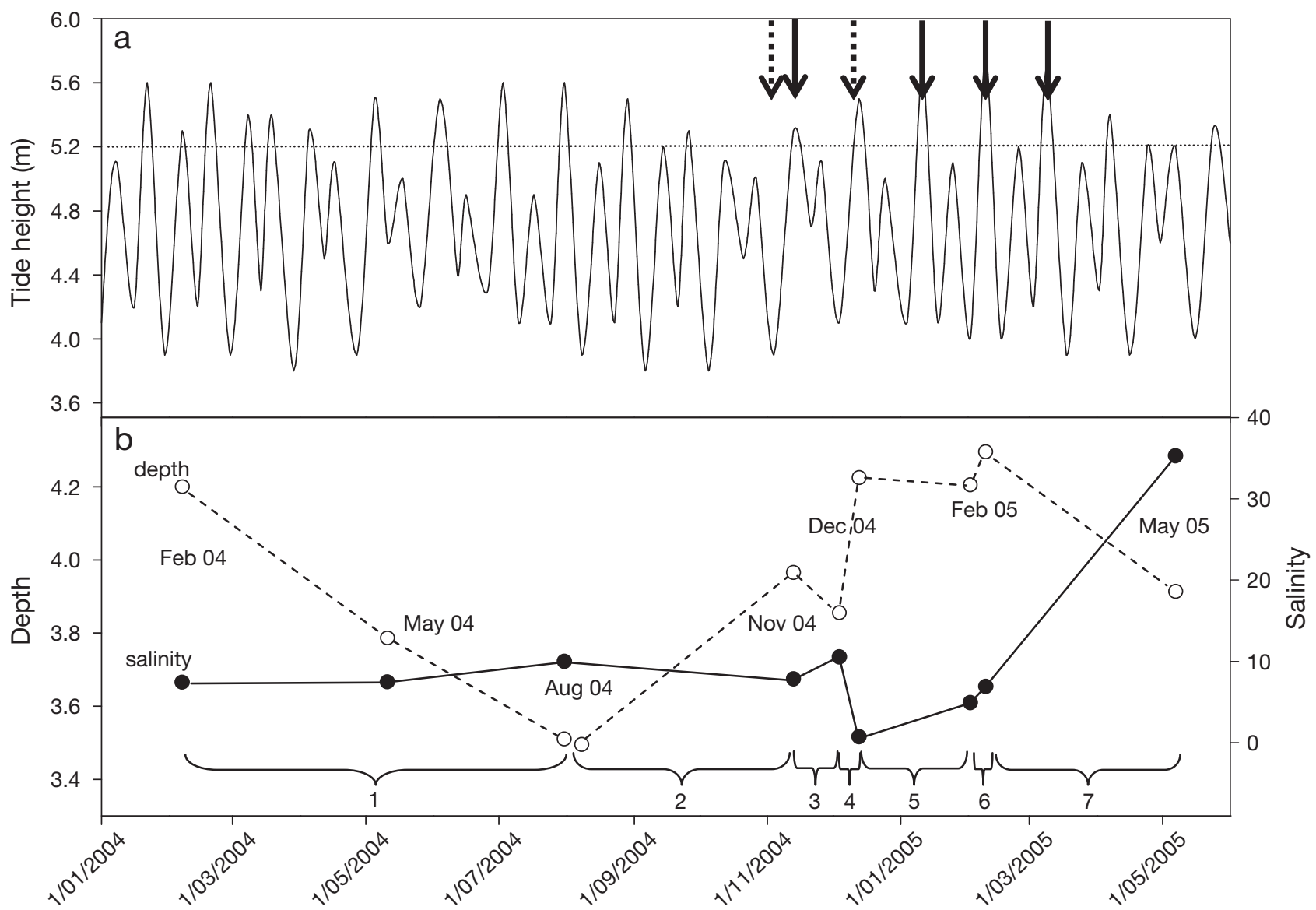

Fig. 3. Sequence of (a) predicted daily maximum tidal height at Port Alma tide gauging station (Seafarer Tides), and (b) depth (O) and mean salinity () of the 12 Mile mesohaline pool from January 2004 to June 2005 (dates given as d/mo/yr). Dotted line in (a) indicates the approximate connection depth for Gonong and Munduran estuarine pools; solid arrows indicate marine connections, dashed arrows beginnings of freshwater connections. Numbered braces in (b) indicate connection-regime periods in the 12 Mile mesohaline pool (see text for details)

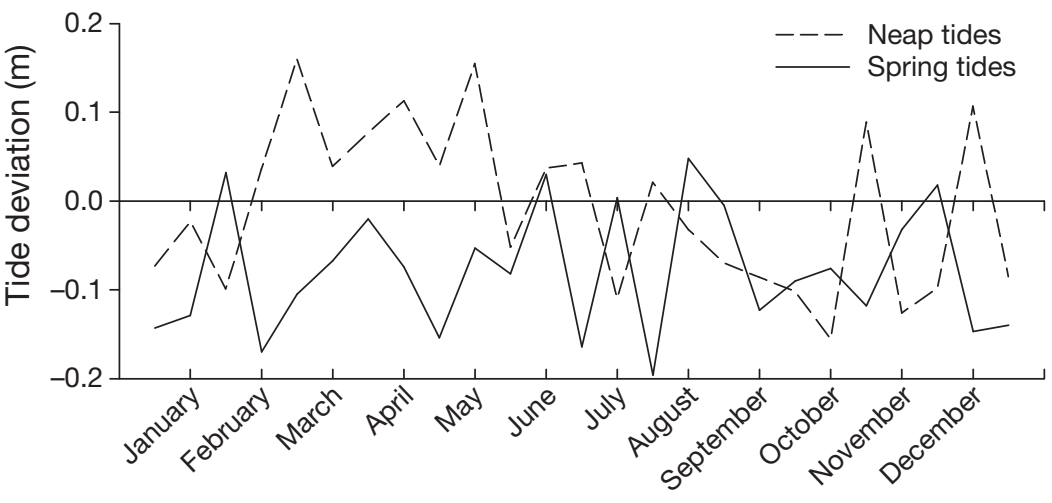

Fig. 4. Sequence of differences between predicted and realised high tides at Port Alma, Queensland, during 2004. Tidal data provided by the Technical Services Division of the Queensland Environmental Protection Agency

water streamflow, suggesting that pre-wetting the $3 \mathrm{~km}$ wide saltpan between 12 Mile mesohaline and Inkerman Creek was a precursor for many marine connections.

\section{Biological connections}

Fishes were captured in cast nets throughout the study from all pools except German Jack's, where no fish were captured when first sampled in November 2004 and salinity was 133\% (Fig. 2a). Cast net catches at all other sites were dominated by phyto-detritivores, principally the clupeid Nematalosa erebi in freshwater pools, and the mugilids Liza subviridis and Mugil cephalus and the scatophagid Selenotoca multifasciata in poikilohaline pools (Table 2).

MDS (Fig. 5a) produced clear groupings of sites (SIMPROF $\mathrm{p}=0.01$ ), an estuarine group (Gonong and Mundunduran estuarine), a group consisting of 12 Mile mesohaline samples, a 12 Mile freshwater group (12 Mile upstream and downstream), an isolated freshwater group (Frogmore 


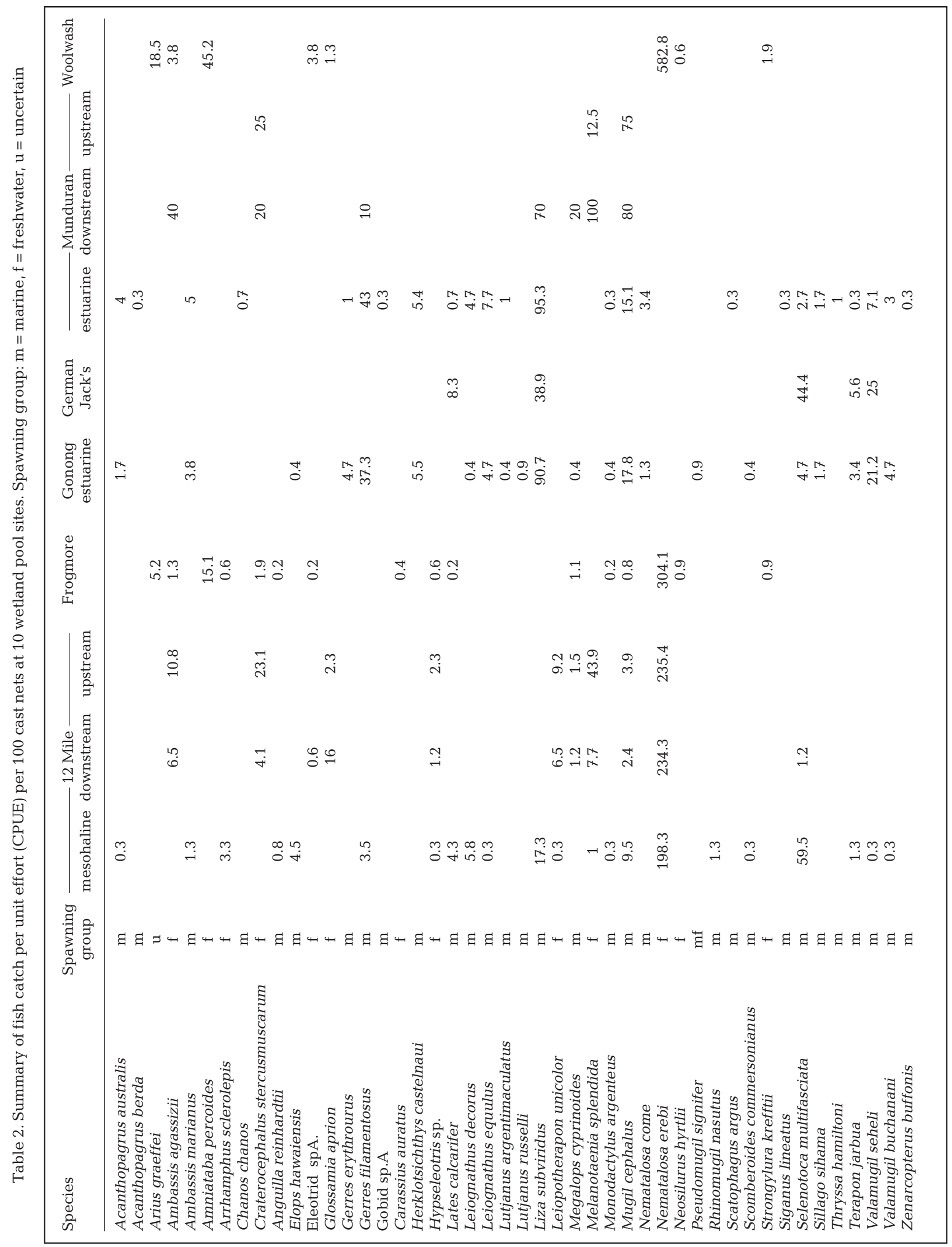




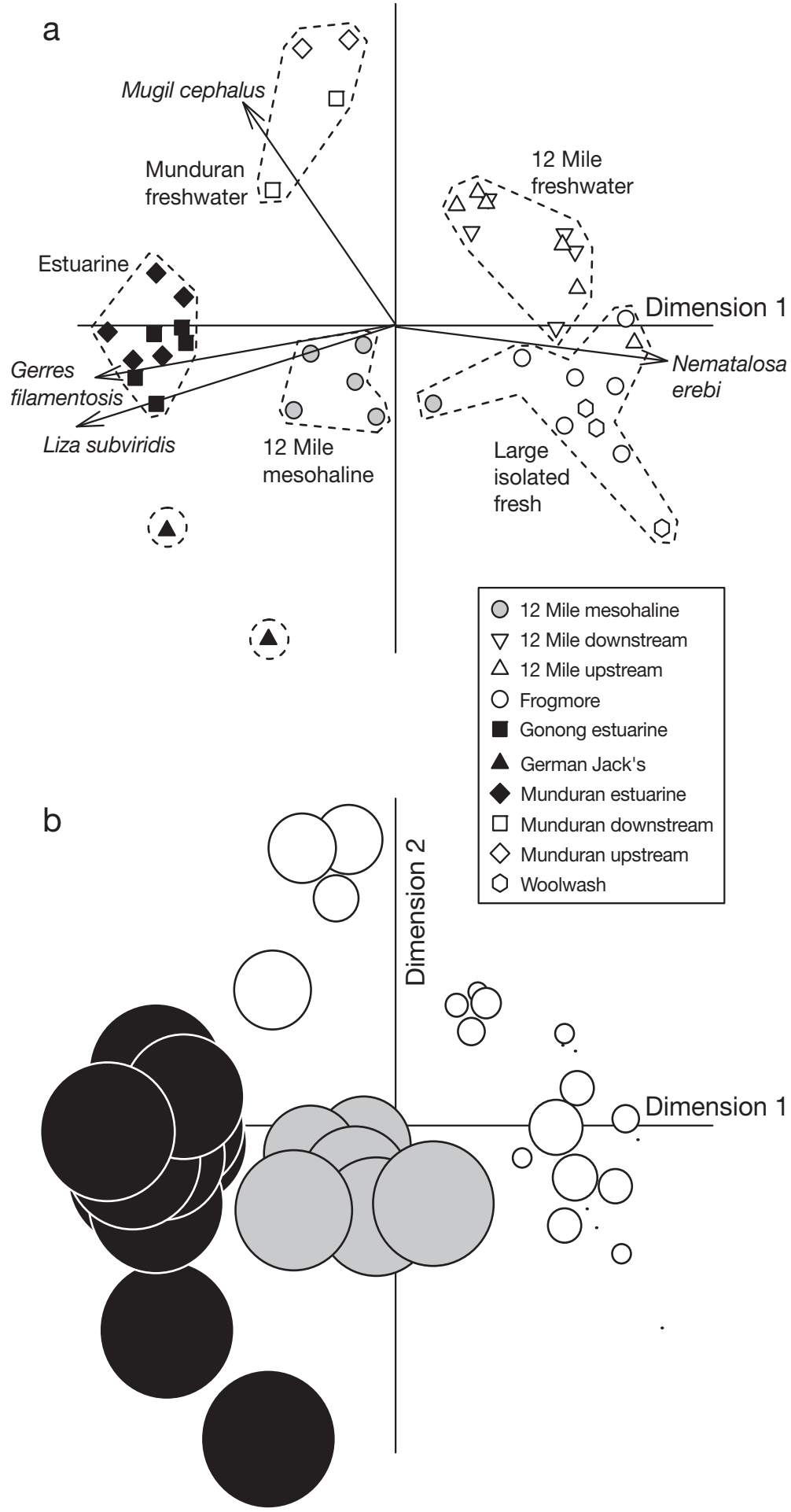

Fig. 5. Two-dimensional multidimensional scaling solution $($ stress $=0.11$ ) for average fish catch per unit effort (CPUE) per 100 cast nets from estuarine wetland pools. (a) Ordination with dashed lines delineating groups that form coherent clusters defined by SIMPROF analysis at $p=0.01$. Vectors indicate the direction of greatest increase in CPUE of the species with the greatest correlation with the ordination space. The length of the vectors is proportional to their $\mathrm{R}^{2}$ value, with the greatest $\mathrm{R}^{2}=0.78$ for Liza subviridis. (b) Ordination with bubble plot overlay indicates the proportion of marine spawners per site (largest bubble $=100 \%$ marine spawners) and Woolwash), a Munduran freshwater group (Munduran upstream and downstream), and 2 outlying German Jack's samples. With the exception of one sample from 12 Mile mesohaline pool in February 2005, these groupings were consistent over time. Isolated freshwater and 12 Mile freshwater sites were characterised by the detritivore Nematalosa erebi, Munduran freshwater sites by the detritivore Mugil cephalus, and estuarine sites by the detritivore Liza subviridis and the benthic feeder Gerres filamentosus. 12 Mile mesohaline sites occupy the centre of the ordination (Fig. 5a), indicating an assemblage with both fresh and marine spawned species. Differences in characteristic species are reflected in complete dominance by marine spawners at estuarine sites, very low proportions of marine spawners at freshwater sites, and a mixture of marine and freshwater spawners at 12 Mile mesohaline (Fig. 5b). In both 12 Mile Creek and Munduran Creek the proportions of fauna comprising marine spawners declined in an upstream direction, from poikilohaline to freshwater pools (Fig. 5b), reflecting decreasing connectivity to fully estuarine waters. Much higher proportions of marine spawners in Munduran freshwater pools than 12 Mile freshwater pools (Fig. 5b) suggest more extensive marine connectivity at Munduran Creek than at 12 Mile Creek and match with shorter distances to the estuary (Munduran downstream 1130 m, 12 Mile downstream $4005 \mathrm{~m}$ ).

Nematalosa erebi was the most commonly captured species in all freshwater sites and 12 Mile mesohaline, and temporal patterns of its CPUE and size structure reflect in-pool conditions and patterns of connectivity. In 12 Mile mesohaline both CPUE and mean size showed strongly curvilinear, negatively correlated $(\mathrm{r}=-0.851$, df $=5, \mathrm{p}=0.034$ ) trajectories (Table 3). Until November 2004 CPUE fell and mean size increased steadily (Fig. 6a). CPUE increased substantially following stream flow from local rainfall in December 2004, but mean size fell precipitously, thus producing a population dominated by small individuals; this suggests a burst of reproduction or recruitment from upstream. Continually increasing mean size was not seen at other sites during this period (Fig. 6), suggesting that there was probably little spawning activity by this freshwater 


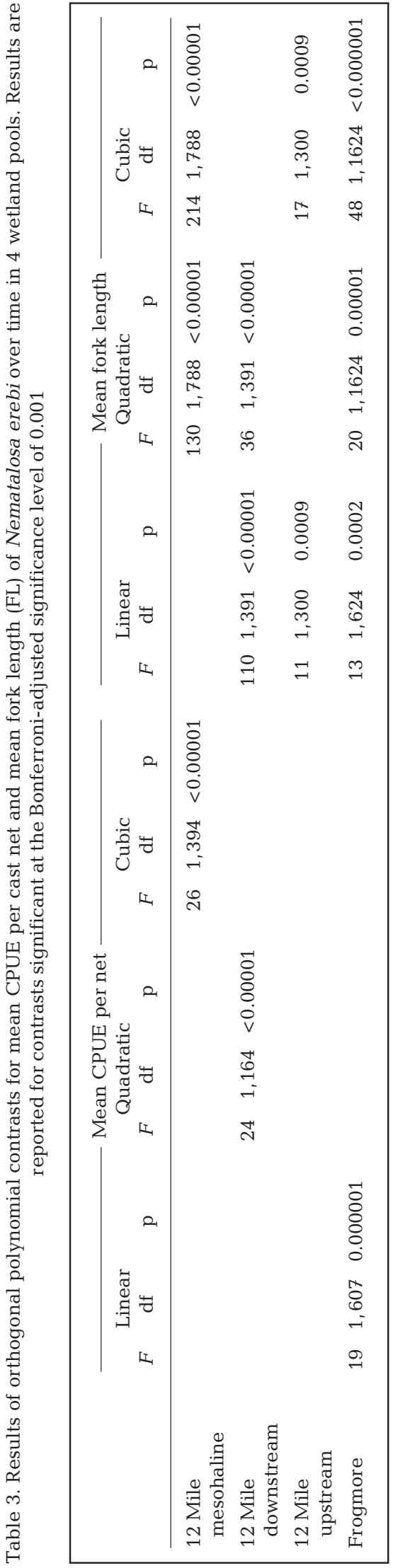

species under the brackish conditions in 12 Mile mesohaline at this time (Fig. 3b). By May 2005 CPUE and mean size had returned to preFebruary 2005 levels, suggesting loss of the abundant small fish, possibly related to unfavourable elevated salinity (Fig. 3b). In contrast, there was neither a consistent negative correlation between CPUE and size nor a strong shift to dominance by small individuals in February 2005 in either 12 Mile freshwater pool (Fig. 6b,c). However, high CPUE in both freshwater pools fell in February 2005 when

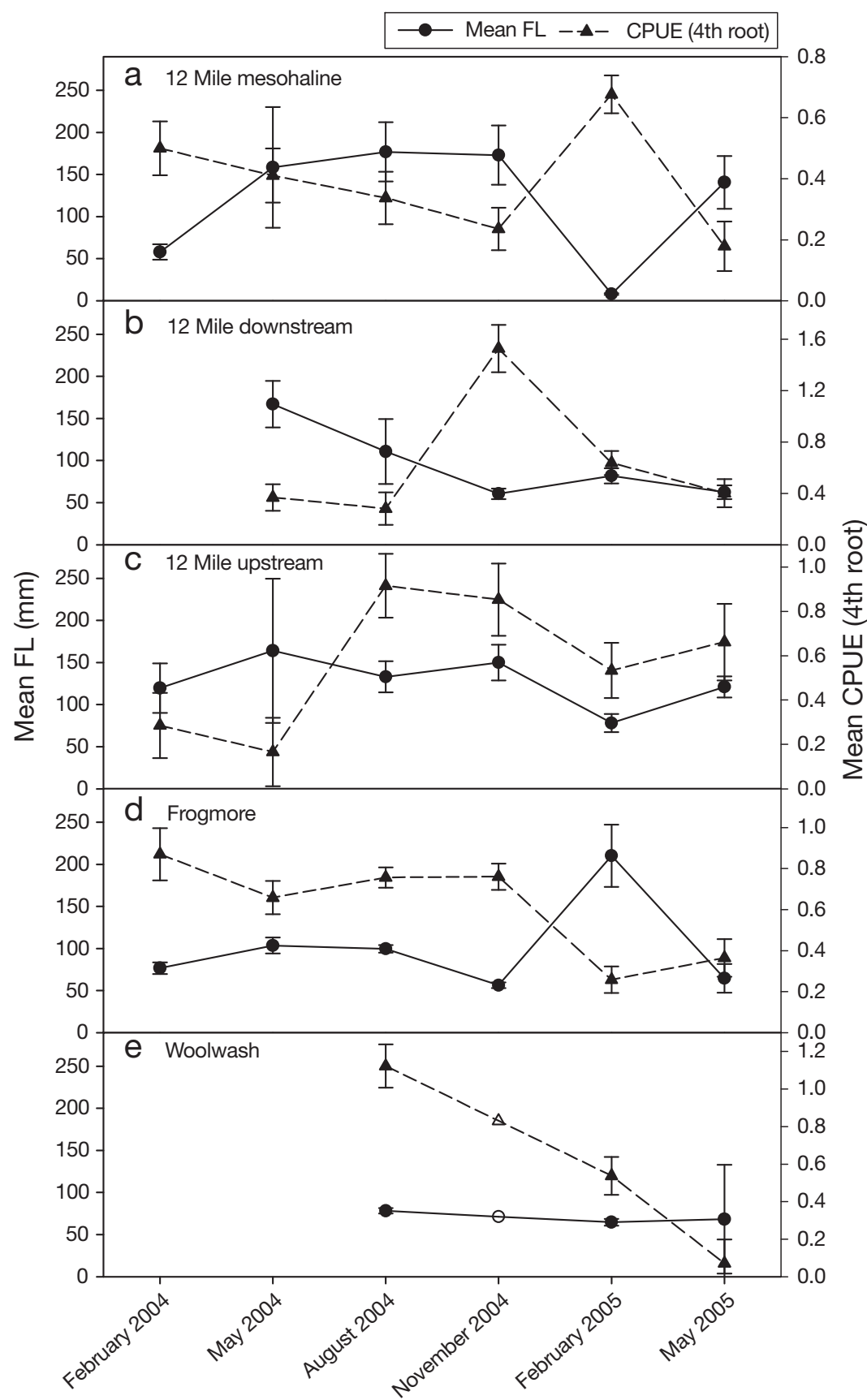

Fig. 6. Changes over time in CPUE per cast net and mean fork length (FL) of Nematalosa erebi in the 12 Mile (a) mesohaline, (b) downstream fresh and (c) upstream fresh pools, and (d) Frogmore and (e) Woolwash. Error bars are $95 \%$ CIs 
CPUE in 12 Mile mesohaline peaked, lending support to the idea of downstream supply from 12 Mile freshwater pools to 12 Mile mesohaline. Frogmore showed the opposite pattern to 12 Mile mesohaline, with mean size increasing in February 2005 as CPUE fell (Fig. 6d). Woolwash showed a consistent decrease in CPUE over the limited sampling occasions but a stable size structure (Fig. 6e). The linear decline in CPUE at Frogmore (Table 2) and Woolwash followed the trend of continual shallowing of the pools (Fig. 2b) due to a lack of connections over the study period (Fig. 2b), and was particularly rapid late in the study when maximum depths declined below ca. $2 \mathrm{~m}$ (Figs. $2 \mathrm{~b} \& 6 \mathrm{~d}, \mathrm{e})$. This matched with the presence of large numbers of piscivorous birds whose ability to catch fish was probably enhanced in the shallow water. Late in 2005 Woolwash dried completely. Size structures of Mugil cephalus (Fig. 7), the marine spawner captured at most sites, also mirrored connectivity. With the exception of 12 Mile upstream fresh, mean and particularly minimum sizes increased as regularity of connection to the estuary proper decreased, presumably reflecting the duration since re-supply of new recruits.

Temporal patterns of CPUE and mean size of the most common species also reflect connectivity among 3 poikilohaline pools. Patterns of CPUE of common marine spawners (Liza subviridis, Selenotoca multifasciata, Gerres filamentosus, Mugil cephalus) in the 12 Mile mesohaline pool were complex, with all except $M$. cephalus showing substantial quadratic or cubic effects (Table 4). The pattern of change was consistent across the marine spawners but contrasted strongly with that of the freshwater spawning Nematalosa erebi (Fig. 8a). As with $N$. erebi the CPUE of marine spawners fell through 2004, but unlike $N$. erebi, which underwent a substantial increase in CPUE following con-

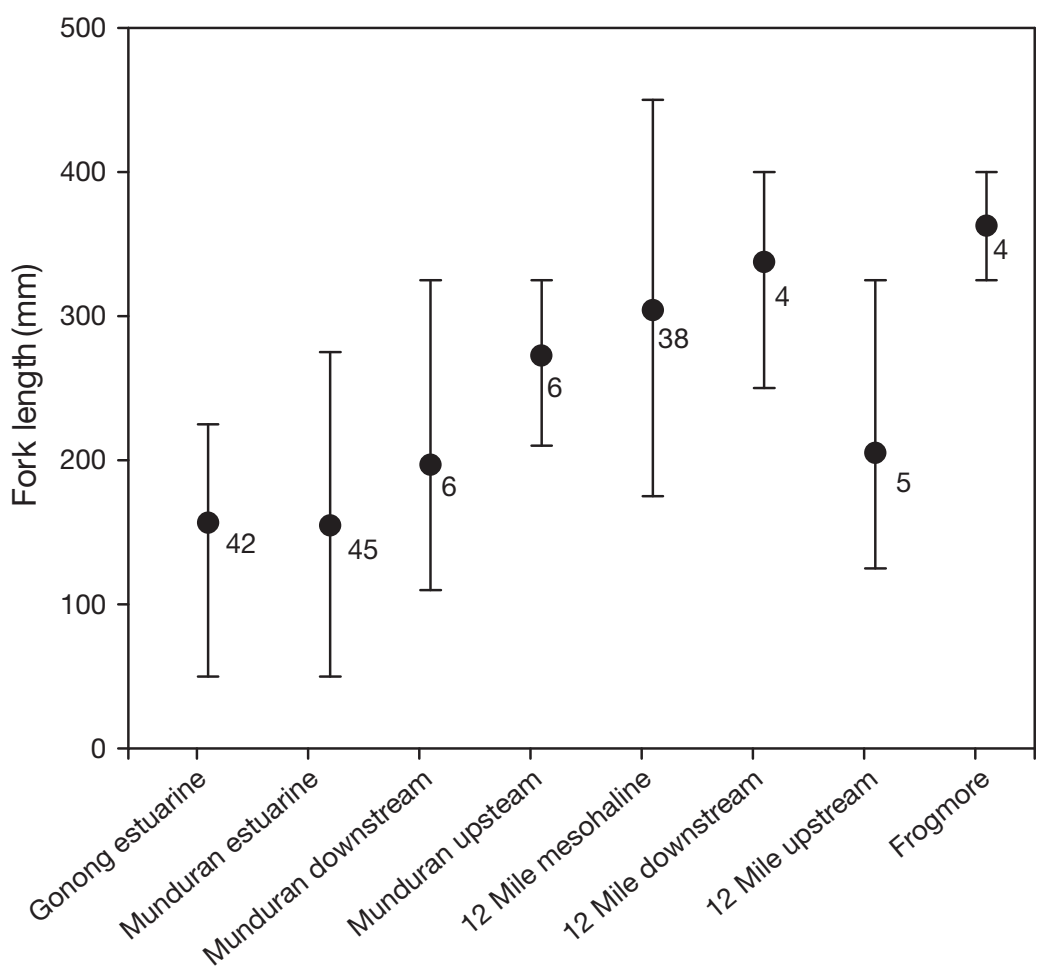

Fig. 7. Size structure (mean, maximum, minimum fork length) of Mugil cephalus. Sites are arranged from left to right in approximate order of decreasing regularity of connection. Numbers next to means indicate sample sizes

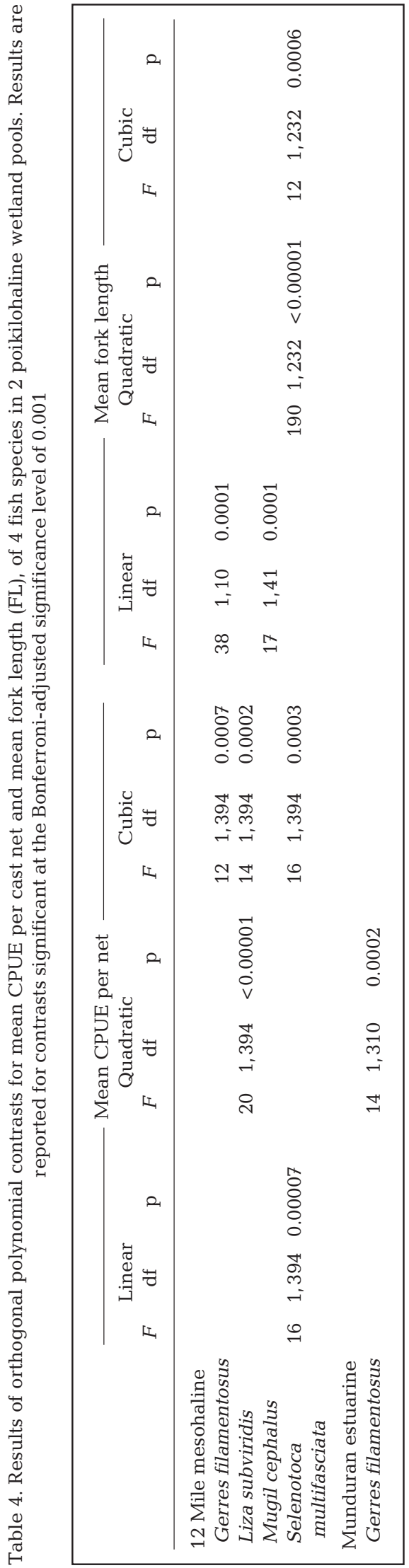




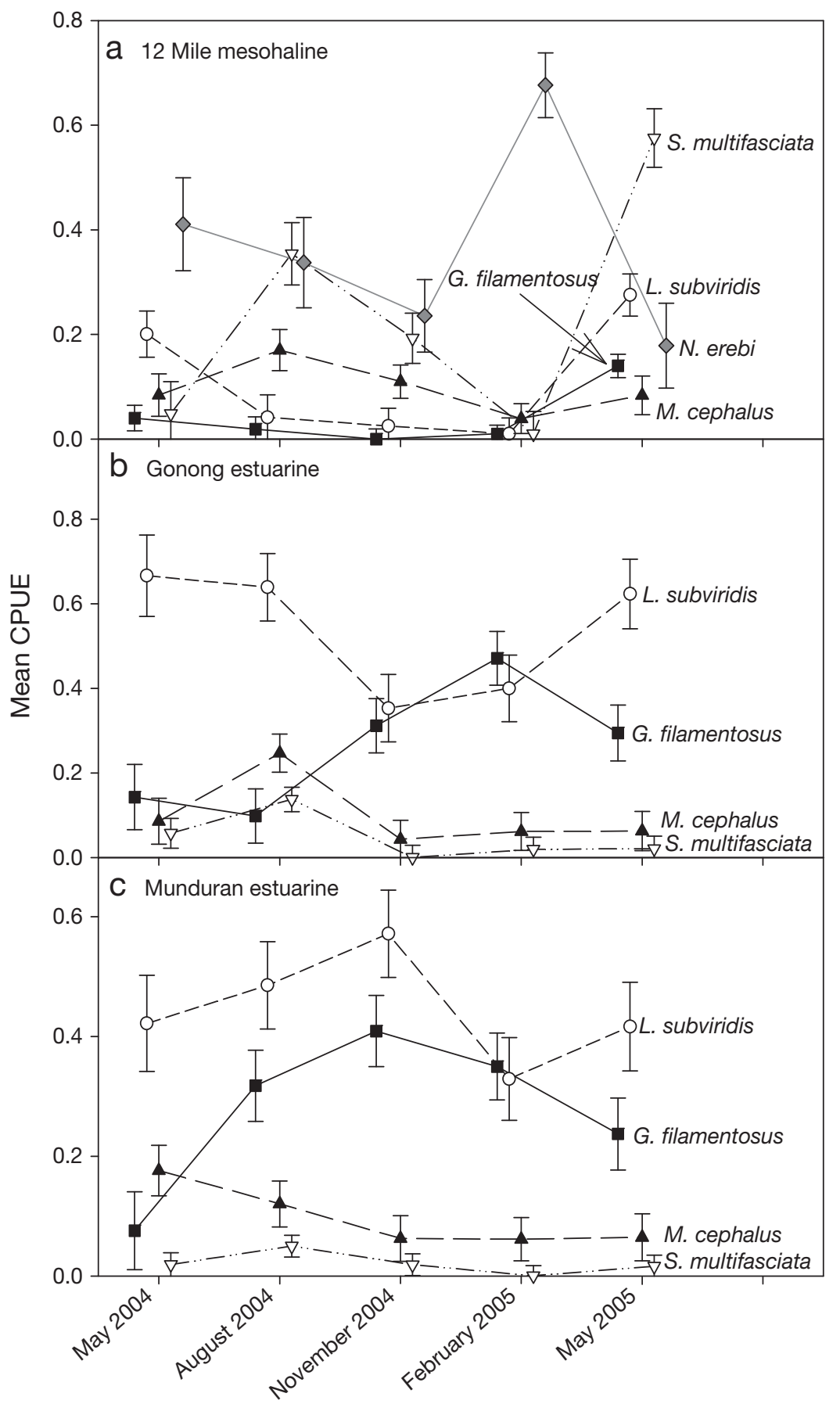

Fig. 8. Changes over time in CPUE per cast net of Gerres filamentosus ( $\mathbf{\square})$, Liza subviridis (๑), Nematalosa erebi $(\diamond)$, Mugil cephalus $(\boldsymbol{\Delta})$, and Selenotoca multifasciata $(\Delta)$ in the (a) 12 Mile mesohaline, (b) Gonong estuarine, and (c) Munduran estuarine pools. Error bars are $95 \%$ CIs nection. Temporal patterns of size of the marine spawners also differed from $N$. erebi at 12 Mile mesohaline (Fig. 9a). $M$. cephalus increased linearly in size over the study (Table 4), indicating no substantial entry of small $M$. cephalus during connections. In contrast, S. multifasciata showed clear curvilinear changes (Table 4), with the appearance of many small individuals resulting in mean size falling to low levels in May 2005 (Fig. 9a) following marine connections, matching with a large increase in abundance (Fig. 8a); this suggests a resupply of small individuals from marine waters. Effects of connectivity on sizes of the other 2 species were more equivocal.

Patterns of temporal change were much weaker at the other 2 poikilohaline pools (Figs. 8b,c \& 9b,c), with only one significant effect: a clear quadratic change in the CPUE of Gerres filamentosus at Munduran estuarine (Table 4). The contrast with the strong patterns at 12 Mile mesohaline seems to reflect the more regular connections to the estuary at Gonong and Munduran estuarine (Figs. $2 \& 3$ ).

In mCART analysis, 4 of the 17 extinction and recolonisation variables explained $60 \%$ of total variance in assemblage composition (Fig. 10a). The primary split was on a recolonisation variable, estuarine connection distance, with sites having a connection distance below $3.6 \mathrm{~km}$ with many more marine spawners than those further from the estuary. Subsequent splits were on extinction variables related to salinity and pool size. Sites closer to the estuary were divided based on salinity (principally salinity regime), and those further from the estuary on surface area. Three extinction and 3 recolonisation variables had high relative importances (Fig. 10b). Important extinction variables related to the longterm nature of the pools, in terms of nection at the end of 2004, CPUEs of marine spawners fell to their lowest levels in February 2005. Subsequently, CPUE of marine spawners had recovered by May 2005, while CPUE of $N$. erebi had declined, suggesting re-supply of marine species during the estuarine connections that followed the initial freshwater conoverall salinity category and variation in salinity and depth, rather than to the physical nature of pools at particular times. Important recolonisation variables related to the degree of connectivity with the estuary and to a lesser extent connectivity with outside sources of freshwater colonists. 


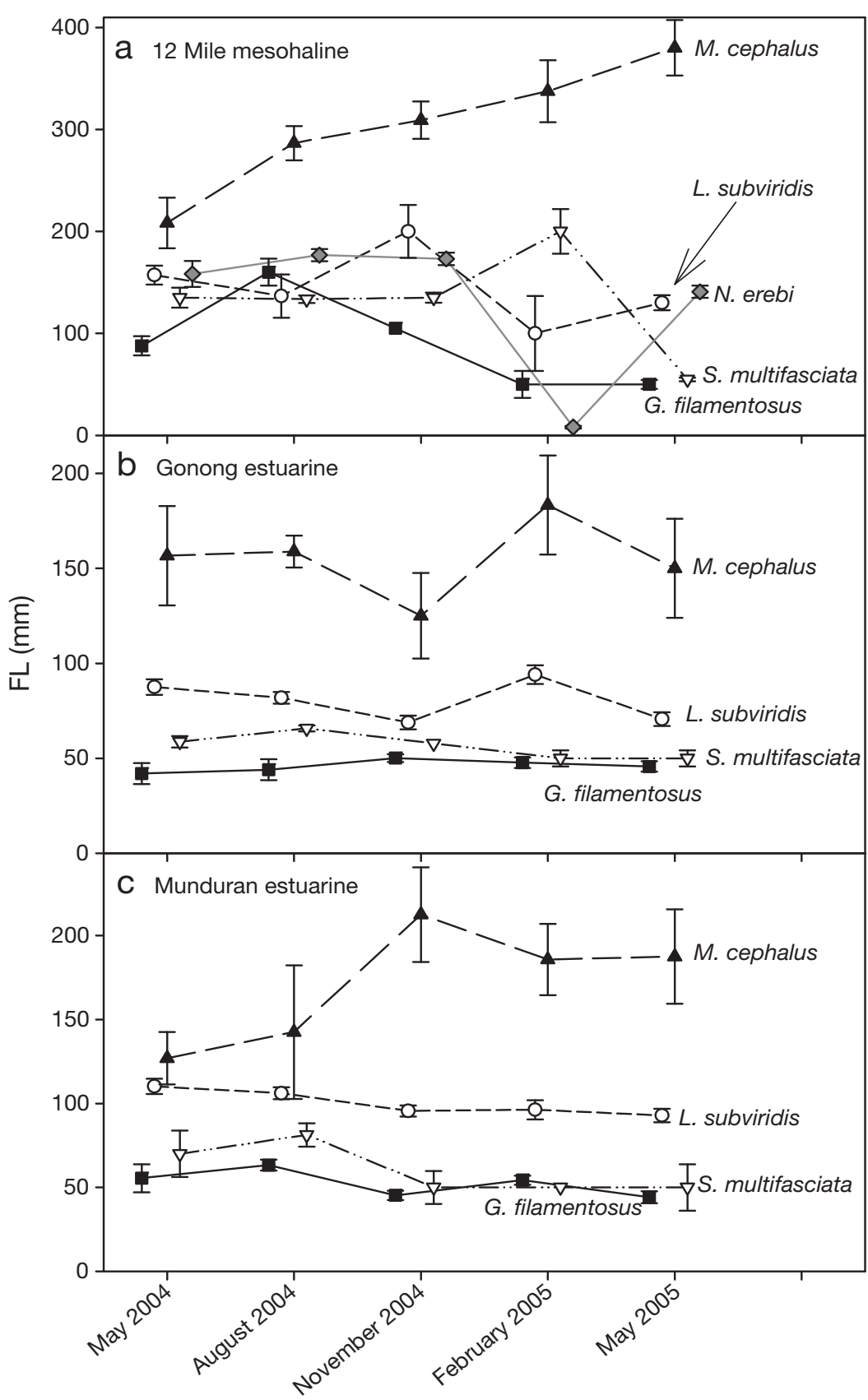

Fig. 9. Changes over time in mean fork length (FL) of Gerres filamentosus ( $\mathbf{\square})$, Liza subviridis $(\bullet)$, Nematalosa erebi $(\diamond)$, Mugil cephalus $(\boldsymbol{\Delta})$, and Selenotoca multifasciata $(\Delta)$ in the (a) 12 Mile mesohaline, (b) Gonong estuarine, and (c) Munduran estuarine pools. Error bars are $95 \%$ CIs

tenuous, leading to a diversity of faunal outcomes. Initial conditions, which are determined by connectivity, interact with the extent, timing, duration and regularity of connection to determine faunal composition, whether or not fish can move between pools, and ultimately whether or not fish utilising a particular pool re-enter and contribute to reproduction in their overall species populations. Thus, connectivity is crucial for both marine species using estuarine wetlands as nurseries (Wenner et al. 1985), and freshwater species that rely on connectivities for re-colonisation of pools and streams following local extinction (Halyk \& Balon 1983).

\section{How tidal and freshwater connections interact to produce biological connections}

Patterns of physical connection and isolation appear to be crucial determinants of the nature of fish fauna in the Fitzroy delta estuarine wetland pools, influencing both the composition of fish assemblages and how they develop over time. Major determinants of differences among pools are the types of connections they experience, which influence salinity regime, and interaction between the size of the pool (particularly depth), the trajectory of change subsequent to connection and the time between connection events.

Three physical factors (major floods, tidal connections and local rainfall) are the primary drivers of biologically meaningful physical connectivity. Major floods periodically reset the system, connecting wetland pools across the floodplain. Although there was no major flood during the study, there was evidence of their past effect in the presence of marine spawned species in the large, isolated Frogmore and Wool-

\section{DISCUSSION}

The Fitzroy delta contains a diversity of estuarine wetland pools encompassing a broad spectrum of salinity regimes and a variety of patterns of physical connectivities. Connectivities to and among estuarine wetland pools of the Fitzroy delta are complex and wash. In the absence of major floods, local storm rainfall events were crucial in producing repeated connections among small pools that were components of intermittent stream systems. These regular connections maintained viable fish assemblages by resupplying individuals, and maintaining water levels and water quality. Moreover, the 12 Mile mesohaline 


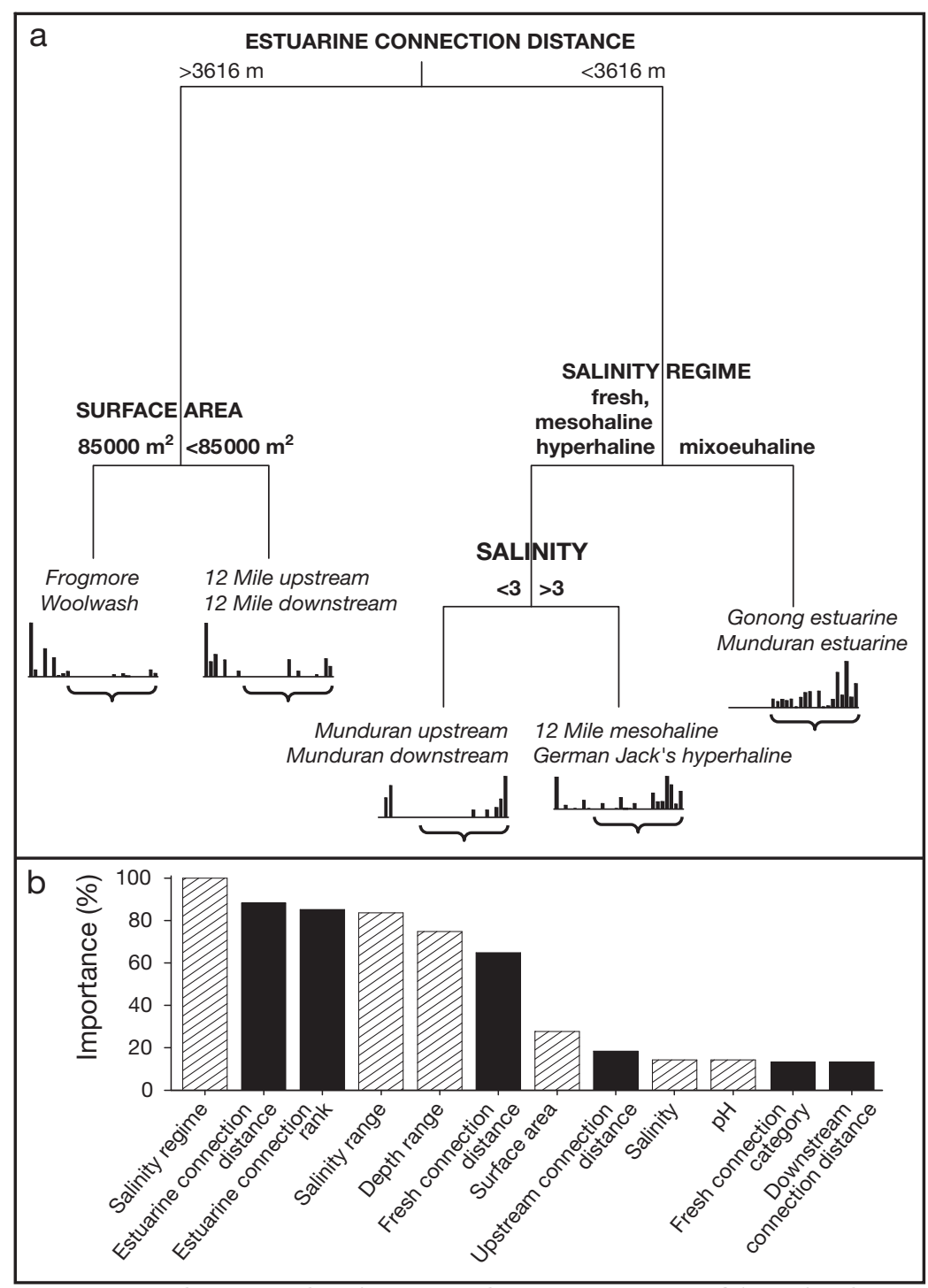

Fig. 10. (a) Multivariate classification and regression tree (mCART) for the importance of extinction and recolonisation variables for the Fitzroy delta estuarine wetland pools; total variance explained $=61 \%$. Length of vertical lines indicates the proportion of variance explained by each split. Bold uppercase text indicates the important factor at each split; lowercase bold text indicates values defining each branch of the splits. Italic text below the terminal branches indicates the sites in each terminal grouping. Histograms indicate the relative CPUE of various species. Individual species are not identified but are presented in the same order in each histogram. Braces under the histograms indicate the marine spawner group. (b) Relative importance of the 12 variables with greatest relative importance in the tree analysis. Hatched bars: extinction variables; black bars: recolonisation variables

pool, which was connected to freshwater pools by storm rainfall, maintained a substantial freshwater fauna that was lacking from poikilohaline pools without such connections. Tidal connections were critical in allowing the estuarine species, which give these wetlands their unique faunal characteristics, to enter the wetland. Although seemingly a simple function of tidal height, in reality these connections were complex.
Tidal anomalies meant that most spring tides failed to reach their predicted heights, which reduced the number, depths and durations of estuarine connection events. In the case of 12 Mile mesohaline the situation was complicated by the need for tidal water to cross an expanse of saltpan to affect connection. The long connection interval meant that the tide needed to remain at a sufficient level long enough for water to flood across the saltpan before connection could occur. This is not simply a function of distance because water would also spread laterally and be slowed by absorption and hydraulic friction (Phelps 1975, Katz et al. 1995). In fact tidal connection to 12 Mile mesohaline seemed to be substantially influenced by the condition of the saltpan surface. Despite a number of tides apparently large enough to cause marine connections during 2004, no connection occurred until after freshwater streamflow flooded the saltpan soaking its surface.

\section{Extent to which variations in connectivity affect fish assemblages}

Physical connectivity performs a dual role in these dry tropic estuarine wetlands: it provides conduits that allow fish to mover through the wetland and it is a primary factor regulating the physical characters of wetland pools. As with other systems (Bennett et al. 1985, Chabrerie et al. 2001) penetration by marine fish into Fitzroy delta pools was limited by connectivity, with a direct relationship between extent of connection and presence of marine spawners. However, unlike more connected systems, the important connectivity conduits (Ray 2005) between freshwater and ocean were only available intermittently, influencing both size structures of marine spawners in isolated pools, and the likelihood of extirpation through dry down, which in turn determines the realised value of pools as nursery and feeding grounds.

The wet season flooding that permits movement of many species in tropical Australian systems (Bishop et al. 1995, Sheaves et al. 2007b) is unreliable in a dry subtropical climate like that of the Fitzroy delta. Here 
major flooding is infrequent and unpredictable making stream flow initiated by local rainfall particularly important. The influence of freshwater connections on fish fauna was not confined to freshwater pools, with flows apparently donating a considerable biomass of the freshwater Nematalosa erebi to the 12 Mile mesohaline pool, so maintaining a mixture of marine and freshwater species, and supporting the high CPUE of predators that utilised $N$. erebi as their major food source (Sheaves et al. 2006).

As well as providing the conduits for the movement of fishes, connections among pools, and between pools and the estuary, are the primary regulator of the physical natures, patterns of physical variability and persistence of pools. These 2 effects of connectivity are intimately interlinked in determining the composition of fish assemblages in Fitzroy delta pools, which are complex mixes of fresh- and marine-spawned species. The interplay of fresh and estuarine connections produced 4 distinct categories of pools: isolated freshwater pools, in-stream freshwater pools, regularly connected poikilohaline pools and infrequently connected poikilohaline pools. Isolated freshwater pools (Frogmore and Woolwash) were only connected by major flooding, and the resulting freshwater environment limited the marinespawned component to a few freshwater-tolerant species. The low frequency of flood connections means pools of this type are constantly at risk of faunal extinction due to dry down. In contrast, regular connections, promoted by local storm rainfall, maintained water levels and provided the opportunity for the regular replenishment of fish that allowed the in-stream freshwater pools (12 Mile and Munduran upstream and downstream) to maintain viable fish fauna despite their small size. Within this group the Munduran pools, which were more closely and directly connected to estuary, had fauna comprising substantially more marine-spawned species than found in the 12 Mile Creek pools.

Frequently connected poikilohaline pools (Gonong and Munduran estuarine) were dominated by marinespawned species, maintained by regular connections that preserved estuarine conditions and promoted the regular interchange of fishes with the estuary. These assemblages were typical of those seen in other northeastern Australian estuaries (e.g. Robertson \& Duke 1987, Sheaves 2006). Infrequently connected poikilohaline pools (12 Mile mesohaline and German Jack's) varied greatly in salinity regimes and faunal identities because of differences in the regularity of connection to freshwater systems. German Jack's lacked regular freshwater inputs, so irregular estuarine connections coupled with evaporation led to hyperhaline conditions and a marine-spawned fauna that did not persist once conditions became hostile. In contrast, regular freshwater connections created a reduced salinity environment in the 12 Mile mesohaline pool and allowed regular replenishment of a freshwater faunal component that coexisted with a substantial marine-spawned component.

The interval between connection events varied greatly among pool types. This variation is reflected in differences in the size structure of Mugil cephalus, the marine spawner captured at the majority of sampling sites. Minimum sizes increased as the regularity of connection to the estuary proper decreased, presumably reflecting the duration since re-supply of new recruits, with smallest sizes in the regularly connected Gonong and Munduran estuarine pools and largest in the isolated Frogmore and Woolwash. Equally as important as the interval between connections is the specific timing of connection events. Marine connections can only provide access to species that are present in the estuary at the time. This is particularly important for larval fish that are often only abundant for short periods of time (Botsford et al. 1998). In contrast, if freshwater connections do not occur often enough to refill pools before dry down makes conditions inhospitable (Townsend \& Edwards 2003, Ostrand \& Wilde 2004) extinction will occur and the role of connection will simply be one of resupply, possibly to a pool which represents a faunal dead end due to regular dry down.

\section{Temporal stability of pool assemblages, and extent to which faunal dynamics are synchronised within and among pool types}

The clear differences in composition between pool fish assemblages were maintained throughout the study period, but individual species CPUE and size structures showed asynchronous temporal variations that reflected the connection histories of the pools.

Low salinity conditions throughout most of the study period enabled the 12 Mile mesohaline pool, which demonstrated the most complex patterns of temporal change seen in any of the pools, to maintain a mixed fauna of marine- and freshwater-spawning species. The dominant freshwater-spawning clupeid Nematalosa erebi showed continually falling CPUE and increasing mean size during an initial long disconnection phase during the first part of the study. Although $N$. erebi can persist in hypersaline lakes, spawning seems restricted to freshwater (Pusey et al. 2004); thus, it is likely that this pattern was due to a lack of spawning activity in the slightly saline conditions preventing the replenishment of small individuals. Alternatively, the pattern of change may have been due to predation on small $N$. erebi from high densities of piscivorous fish like Lates calcarifer that prey heavily on $N$. erebi (Sheaves et al. 2006). Following a freshwater connection event in late 2004 a large increase in CPUE of 
$N$. erebi coupled with a substantial decrease in mean size strongly suggested resupply from freshwater pools higher up the 12 Mile Creek system. Marine spawners showed a very different pattern in 12 >Mile mesohaline, with marked decreases in CPUE over time culminating in very low CPUE following freshwater connection. This suggests emigration to the estuary during the freshwater connection event. CPUE of marine spawners rebounded strongly following connection to the estuary in early 2005, presumably the result of immigration of marine species.

In contrast to the fluctuating pattern in the 12 Mile mesohaline pool driven by alternating fresh and marine connections, changes in CPUE and mean size of $\mathrm{Ne}$ matalosa erebi were more conservative in the two 12 Mile Creek freshwater pools. Their patterns of change were fairly synchronous, which is not surprising given their similar physical conditions and adjacent positions in the 12 Mile Creek system that led to contemporaneous freshwater connections. Similarly, the major species in Gonong and Munduran estuarine pools showed concordant patterns of change over time, with both CPUE and mean size remaining relatively constant throughout the study, reflecting their regular connections with the estuary proper. Frogmore and Woolwash, the 2 isolated freshwater pools, also showed a degree of synchrony, with declines in Nematalosa erebi CPUE matching declining water levels, particularly when maximum pool depths declined below ca. $2 \mathrm{~m}$. CPUE of $N$. erebi might have been expected to increase as pool volumes decreased, as is the case for many (Chapman et al. 1991, Faunce \& Paperno 1999), but not all (Ostrand \& Wilde 2004), species in isolated pools. In this case, the counterintuitive declines of $N$. erebi CPUE as volumes decreased were probably due to both their sensitivity to degradation in water quality, particularly low dissolved oxygen (Townsend \& Edwards 2003), and to extensive mortality from high abundances of piscivorous birds that increased progressively as the pools reached shallow levels (Sheaves et al. 2006).

\section{Importance of extinction- and recolonisation-related factors in determining fish assemblage composition}

CART analysis indicated that a recolonisation variable (the connection distance between pools and the estuary) explained the largest proportion of variability in fish assemblage composition, with wetland pools closer to the estuary having a greater contribution from marine spawned species. While extinction variables were also important, it was those relating to the longterm nature of the pool environments (salinity regime and variation, variation in depth, pool size) that mainly affected composition, rather than variables relating to the physical environment of pools at specific times. Consequently, the majority of important extinction variables (salinity regime, salinity variation, variation in depth) were those heavily influenced by patterns of connectivity. This contrasts with small temperate freshwater lakes for which extinction variables are often more important than recolonisation variablies in structuring fish assemblabes (e.g. Tonn \& Magnuson 1982, Rahel 1984, Tonn et al. 1995, Magnuson et al. 1998). In these systems, the primacy of extinction variables is explained by a much lower probability of connection than extinction (Tonn et al. 1995, Magnuson et al. 1998). The opposite is the case for many Fitzroy delta wetland pools, where regular, if unreliable, connections to other pools and/or the estuary mean that the probability of recolonisation is high. However, in more isolated pools, like Frogmore, Woolwash and German Jack's, reconnection may occur infrequently enough to bring extinction to the forefront, although the balance between extinction and recolonisation (Barbour \& Brown 1974, Tonn et al. 1995) is likely to be uncertain in this highly variable climate. Climatic variability is likely to increase as global climate change intensifies (Lough 2001), leading to an increase in the likelihood of extinction. Because of their nursery ground role, a shift towards a greater incidence of extinction events has substantial implications for estuarine wetland pools. As the incidence of extinction increases, the value of individual isolated pools will decrease because both the chance of repopulation (Hudson \& Cattadori 1999) and the likelihood of exporting fish to other habitats will decrease. At the same time the need to conserve the more highly connected pools will increase as the loss of alternative nursery pools increases their importance as nursery habitats.

Distinct suites of extinction and recolonisation variables exist in many temperate lake situations (e.g. Barbour \& Brown 1974, Magnuson et al. 1998). This is not the case for the Fitzroy estuarine wetlands, where connectivity has a pervasive influence on both recolonisation and extinction variables, making it a primary factor regulating the composition and persistence of fish fauna. By providing passage among wetland pools and between wetland pools and the estuary, connectivity is the primary factor facilitating recolonisation of estuarine wetland pools in the Fitzroy delta. At the same time connectivity is also a principal factor determining population change, with populations of less frequently connected pools showing consistent changes in CPUE and size during disconnection periods and rapid changes following connection events. Additionally, connectivity factors, like the interval between connection events, the relative isolation of pools and the type of connection (estuarine or fresh), interact with pool attributes like depth and areal extent to determine the potential for extinction. 


\section{Metapopulation dynamics}

The fish fauna of Fitzroy delta estuarine wetland pools fulfil metapopulation criteria: local populations with a high probability of extinction, existing in discrete habitat patches linked by dispersal that allows recolonisation (Hanski 1999). Additionally, varying patters of connectivity produce asynchronous dynamics, another signature of metapopulation dynamics (Hanski 1999). However, the metapopulation structure is complex, demonstrating both classic and source-sink dynamics (Freckleton \& Watkinson 2002). Freshwater spawning fishes show classic dynamics, with persistence governed by the processes of extinction and recolonisation. In contrast, marine spawners show source-sink dynamics, with most pools incapable of supporting persistent local populations, but with a marine-spawned component maintained by immigration from estuary source populations. This contrasts with reef fish populations in the same region which are enhanced by source-sink dynamics (Bode et al. 2006) but where there is a low probability of extinction (Kritzer \& Sale 2004). The Fitzroy delta wetland pools also differ from many other metapopulation situations in that extinction factors, such as salinity regime, salinity variation, and variation in depth, are heavily influenced by connectivity rather than being independent of it.

Unfortunately, a lack of comparable studies makes it impossible to assess the generality of the understanding of connectivity and metapopulation structure in dry subtropical estuarine wetlands developed here. However, at a general level it is clear that the extent to which different species are able to utilise tropical estuarine wetlands is fundamentally dependent on small changes in rainfall patterns, freshwater inflow or tidal levels that profoundly affect connectivity and its complex interactions with crucial life-history events (e.g. the match between recruit availability and timing of connectivity). Thus, this preliminary understanding at least provides a basic conceptual outline that can be tested and refined in other dry subtropical and tropical areas around the world.

Acknowledgements. This project was supported by a grant from the Cooperative Research Centre for Coastal Zone, Estuary and Waterway Management. We thank K. Abrantes, R. Baker, A. Penny, L. Ortiz Guerra, B. Packett and P. Verwey for their valuable field assistance, and 4 reviewers for their valuable comments.

\section{LITERATURE CITED}

Adamowicz SC, Roman CT (2005) New England salt marsh pools: a quantitative analysis of geomorphic and geographic features. Wetlands 25:279-288

Baker R, Sheaves M (2005) Redefining the piscivore assemblage of shallow estuarine nursery habitats. Mar Ecol Prog Ser 291:197-213
Baker R, Sheaves M (2007) Shallow-water refuge paradigm: conflicting evidence from tethering experiments in a tropical estuary. Mar Ecol Prog Ser 349:13-22

Barbour CD, Brown JH (1974) Fish species diversity in lakes. Am Nat 108:473-489

Bennett BA, Hamman KCD, Branch GM, Thorne SC (1985) Changes in the fish fauna of the Bot River Estuary in relation to opening and closure of the estuary mouth. Trans R Soc S Afr 45:449-464

Bishop KA, Pidgeon RWJ, Walden DJ (1995) Studies on fish movement dynamics in a tropical floodplain river: Prerequisites for a procedure to monitor the impacts of mining. Aust J Ecol 20:81-107

Bode M, Bode L, Armsworth PR (2006) Larval dispersal reveals regional sources and sinks in the Great Barrier Reef. Mar Ecol Prog Ser 308:17-25

Botsford LW, Moloney CL, Largier JL, Hastings A (1998) Metapopulation dynamics of meroplanktonic invertebrates: the Dungeness crab (Cancer magister) as an example. Can Spec Publ Fish Aquat Sci 125:295-306

Breiman L, Friedman JK, Olshen RA, Stone CJ (1984) Classification and regression trees. Wadsworth International Group, Belmont, CA

Brockmeyer RE Jr, Rey JR, Virnstein RW, Gilmore RG, Earnest L (1997) Rehabilitation of impounded estuarine wetlands by hydrologic reconnection to the Indian River Lagoon, Florida (USA). Wetlands Ecol Manag 4:93-109

Bruinsma C (2001) Queensland coastal wetland resources: Cape Tribulation to Bowling Green Bay. Queensland Department of Primary Industries, Brisbane

Chabrerie O, Poudevigne I, Bureau F, Vinceslas-Akpa M and others (2001) Biodiversity and ecosystem functions in wetlands: a case study in the estuary of the Seine River, France. Estuaries 24:1088-1096

Chapman LJ, Kramer DL, Chapman CA (1991) Population dynamics of the fish Poecilia gillii (Poeciliidae) in pools of an intermittent tropical stream. J Anim Ecol 60: $441-453$

Clarke KR, Gorley RN (2006) PRIMER v6: user manual/tutorial. PRIMER-E, Plymouth

Costa MJ, Catarino F, Bettencourt A (2001) The role of salt marshes in the Mira estuary (Portugal). Wetlands Ecol Manag 9:121-134

Dahl E (1956) Ecological salinity boundaries in poikilohaline waters. Oikos 7(I):1-21

De'ath G (2002) Multivariate regression trees: a new technique for modeling species-environment relationships. Ecology 83:1105-1117

Eyre B (1998) Transport, retention and transformation of material in Australian estuaries. Estuaries 21:540-551

Faunce CH, Paperno R (1999) Tilapia-dominated fish assemblages within an impounded mangrove ecosystem in eastcentral Florida. Wetlands 19:126-138

Freckleton RP, Watkinson AR (2002) Large-scale spatial dynamics of plants: metapopulations, regional ensembles and patchy populations. J Ecol 90:419-434

Froese R, Pauly D (eds) (2007) FishBase. World Wide Web electronic publication. Available at: www.fishbase.org, version $(11 / 2007)$

Gelwick FP, Akin S, Arrington DA, Winemiller KO (2001) Fish assemblage structure in relation to environmental variation in a Texas Gulf coastal wetland. Estuaries 24:285-296

Gilmore RG (1995) Environmental and biogeographic factors influencing ichthyofaunal diversity: Indian River Lagoon. Bull Mar Sci 57:153-170

Grimm V, Reise K, Strasser M (2003) Marine metapopulations: a useful concept? Helgol Mar Res 56:222-228 
Halyk LC, Balon EK (1983) Structure and ecological production of the fish taxocene of a small floodplain system. Can J Zool 61:2446-2464

> Hanski I (1998) Metapopulation dynamics. Nature 396:41-49

Hanski I (1999) Metapopulation ecology. Oxford University Press, Oxford

> Hudson PJ, Cattadori IM (1999) The Moran effect: a cause of population synchrony. Trends Ecol Evol 14:1-2

Johnston R, Sheaves M, Molony B (2007) Are distributions of fish in tropical estuaries influenced by turbidity over small spatial scales? J Fish Biol 71:657-671

Katz DM, Watts FJ, Burroughs ER (1995) Effects of surface roughness and rainfall impact on overland flow. J Hydraul Eng 121:546-553

Kritzer JP, Sale PF (2004) Metapopulation ecology in the sea: from Levins' model to marine ecology and fisheries science. Fish Fish 5:131-140

Laffaille P, Feunteun E, Lefeuvre J (2000) Composition of fish communities in a european macrotidal salt marsh (the Mont Saint-Michel Bay, France). Estuar Coast Shelf Sci 51:429-438

Lough JM 2001, Climate variability and change on the Great Barrier Reef. In: Wolanski E (ed) Oceanographic processes on coral reefs: physics-biology links in the Great Barrier Reef. CRC Press, Boca Raton, FL, p 269-300

Magnuson JJ, Tonn WM, Banerjee A, Toivonen J, Sanchez O, Rask M (1998) Isolation vs. extinction in the assembly of fishes in small northern lakes. Ecology 79:2941-2956

Mazzotti FJ, Fling HE, Merediz G, Lazcano M, Lasch C, Barnes T (2005) Conceptual ecological model of the Sian Ka'An Biosphere Reserve, Quintana Roo, Mexico. Wetlands 25:980-997

McCune B, Grace JB (2002) Analysis of ecological communities. MjM Software Design, Gleneden Beach, OR

> Ostrand KG, Wilde GR (2004) Changes in prairie stream fish assemblages restricted to isolated streambed pools. Trans Am Fish Soc 133:1329-1338

Phelps HO (1975) Shallow laminar flows over rough granular surfaces. J Hydraul Eng 101:367-384

Por FD (1972) Hydrobiological notes on the high-salinity waters of the Sinai Peninsula. Mar Biol 14:111-119

Pusey B, Kennard M, Arthington A (2004) Freshwater fishes of north-eastern Australia. CSIRO Publishing, Collingwood

Rahel FJ (1984) Factors structuring fish assemblages along a bog lake successional gradient. Ecology (Wash DC) 65(4): 1276-1289

Ray GC (2005) Connectivities of estuarine fishes to the coastal realm. Estuar Coast Shelf Sci 64:18-32

Robertson AI, Duke NC (1987) Mangroves as nursery sites: comparisons of the abundance and species composition of fish and crustaceans in mangroves and other nearshore habitats in tropical Australia. Mar Biol 96:193-205

Rozas LP, Hackney CT (1983) The importance of oligohaline estuarine wetland habitats to fisheries resources. Wetlands 3:77-89

Ruetz CR III, Trexler JC, Jordan F, Loftus WF, Perry SA (2005) Population dynamics of wetland fishes: spatio-temporal patterns synchronized by hydrological disturbance? J Anim Ecol 74:322-332

Russ GR (2002) Yet another review of marine reserves as reef fishery management tools. In: Sale PF (ed) Coral reef fishes: dynamics and diversity in a complex ecosystem. Academic Press, San Diego, CA, p 421-443

Schorr MS, Meador MR, Hill LG (1995) Incidental catch of sport fish in cast nets used to collect baitfish in Lake Texoma, Oklahoma-Texas. N Am J Fish Manag 15:142-147
Semeniuk V, Semeniuk TA, Unno J (2000) The Leschenault Inlet estuary: an overview. J R Soc West Aust 83:207-228

Sheaves M (2005) Nature and consequences of biological connectivity in mangrove systems. Mar Ecol Prog Ser 302:293-305

Sheaves M (2006) Scale-dependent variation in composition of fish fauna among sandy tropical estuarine embayments. Mar Ecol Prog Ser 310:173-184

Sheaves M, Collins J, Houston W, Dale P, Revill A, Johnston R, Abrantes K (2006) Contribution of floodplain wetland pools to the ecological functioning of the Fitzroy River Estuary. Cooperative Research Center for Coastal Zone, Estuarine and Waterway Management, Indooroopilly

Sheaves M, Abrantes K, Johnston R (2007a) Nursery ground value of an endangered wetland to juvenile shrimps. Wetlands Ecol Manag 15:311-327

Sheaves M, Johnston R, Molony B, Shepard G (2007b) The effect of impoundments on the structure and function of fish fauna in a highly regulated dry tropics estuary. Estuar Coasts 30:507-517

Sheaves M, Johnston R, Abrantes K (2007) Fish fauna of dry sub-tropical estuarine floodplain wetlands. Mar Freshw Res 58(10):931-943

Sheldon F, Thoms MC (2006) Relationships between flow variability and macroinvertebrate assemblage composition: Data from four Australian dryland rivers. River Res Appl 22:219-238

Shreffler DK, Simenstad CA, Thom RM (1992) Foraging by juvenile salmon in a restored estuarine wetland. Estuaries 15:204-213

Smedbol RK, McPherson A, Hansen MM, Kenchington E (2002) Myths and moderation in marine 'metapopulations'? Fish Fish 3:20-35

Sokal RR, Rohlf FJ (1981) Biometry: the principles and practice of statistics in biological research, 2nd edn. WH Freeman, New York

Stevens PW (2006) Sampling fish communities in saltmarsh impoundments in the northern Indian River Lagoon, Florida: cast net and culvert trap gear testing. Fla Sci 69:135-147

Stevens PW, Montague CL, Sulak KJ (2006) Patterns of fish use and piscivore abundance within a reconnected saltmarsh impoundment in the northern Indian River Lagoon, Florida. Wetlands Ecol Manag 14:147-166

Tonn WM, Magnuson JJ (1982) Patterns in the species composition and richness of fish assemblages in northern Wisconsin lakes. Ecology 63:1149-1166

Tonn W, Vandenbos R, Paszkowski C (1995) Habitat on a broad scale: relative importance of immigration and extinction for small lake fish assemblages. Bull Fr Peche Piscicult 337/338:47-61

Townsend SA, Edwards CA (2003) A fish kill event, hypoxia and other limnological impacts associated with early wet season flow into a lake on the Mary River floodplain, tropical northern Australia. Lakes Reservoirs: Res Manag 8:169-176

Webster IT, Ford PW, Robson B, Margveashvili N, Parslow J (2003) Conceptual models of the hydrodynamics, fine sediment dynamics, biogeochemistry and primary production in the Fitzroy Estuary. Report No. 8, Cooperative Research Centre for Coastal Zone Estuary and Waterway Management, Indooroopilly

Wenner CA, Beatty HR, Roumillat WA (1985) Comparisons of the ichthyofauna in South Carolina coastal wetland impoundments and adjacent tidal creeks. Estuaries 8:41A (Abstract) 